\title{
LSD-25 and exploration in the rat*
}

\author{
G. LOWE and D. I. WILLIAMS \\ The University. Hull HU6 $7 R X$, England
}

\begin{abstract}
Exploration in rats may be categorized as response for. or response to, stimulation. LSD-25 has been shown to depress responding for response-contingent stimulation. The present study, using a situation where inspection of a stimulus card is measured, showed that LSD-25 increased responding to a stimulus. Thus, the previous result was not due to reduction of activity by the drug. The finding is consistent with an arousal theory of exploration.
\end{abstract}

Rats explore. In discussing this behavior, a distinction must be drawn between an animal's response to stimulation and an animal's response for stimulation (cf. Fowler, 1965). Differences in behavior in the two situations have a simple interpretation in terms of an arousal theory of exploration (cf. Berlyne, 1969). For example, if it is supposed that there is an optimal level of arousal, an animal in this state will not seek (respond for) stimulation to increase arousal level. If, however, such an animal is exposed to stimulation, it may well respond to it, thereby rendering it less novel and thus reducing its arousal potential so that input from the environment is reduced to an optimal level.

It has been shown (Lowe \& Williams, 1972) that LSD-25 depresses responding by rats for response-contingent light change. This, it is argued, is because the drug increases arousal level and so reduces the "need" for further stimulation. In this situation, an animal responds for stimulation. A rather different prediction would be made in a situation where a response was made to stimulation. Here, if our hypothesis is correct, no depression of exploratory behavior would be shown; in fact, an increase in responding would be expected. The prediction is tested in this study by looking at the effect of the drug on an animal's inspection of a stimulus card in an apparatus similar to that used by Berlyne (1955).

\section{METHOD}

\section{Subjects}

Thirty-six male black hooded rats (strain PCG/C), aged approximately 90 days, were used as Ss. They were raised and maintained with free access to food and water under normal laboratory conditions, with a light cycle of $17 \mathrm{~h}$ light $/ 7 \mathrm{~h}$ darkness.

\section{Apparatus}

The apparatus consisted of a box with fitted lid constructed in white Perspex. This was $24 \mathrm{~cm}$ deep. The end wall was $18 \mathrm{~cm}$

*The authors gratefully acknowledge the assistance of Brenda Miller and Isla Reid. This research was supported by a grant from the Medical Research Council. wide: the side walls at right angles to this extended for $20 \mathrm{~cm}$. Two further $15-\mathrm{cm}$ lengths were set at an angle of $115 \mathrm{deg}$ to the main wall so that the box narrowed to a width of $5 \mathrm{~cm}$; the side walls continued for another $5 \mathrm{~cm}$ parallel to the main wall to give a box with a floor area $5 \mathrm{~cm}$ square. Across the entrance to this box was a ledge on the floor, $1 \mathrm{~cm}$ high, and a brass bar at a height of $4.5 \mathrm{~cm}$. One centimeter behind the bar and $2 \mathrm{~cm}$ above the floor was situated a light beam; breaking the beam operated a photocell and thence a printout counter which printed cumulative frequency every $5 \mathrm{~min}$. At the very end of the box was a clear Perspex window, $5 \mathrm{~cm}$ square, behind which could be displayed a stimulus card. The stimulus card was either "simple"-a card bisected vertically with half white and half black-or "complex," where the card was divided into four quadrants, each divided diagonally, the half above the diagonal being black and the half below, white. The box was illuminated by a $60-\mathrm{W}$ lamp suspended $25 \mathrm{~cm}$ above the lid.

\section{Procedure}

Each rat was given an intraperitoneal injection $10 \mathrm{~min}$ prior to being placed in the experimental box. Half the animals received LSD-25 $(0.2 \mathrm{mg} / \mathrm{kg})$ and half $0.9 \%$ isotonic saline. The rat remained in the box for $20 \mathrm{~min}$. Half the animals in each condition had the "simple" stimulus card and half the "complex." The measured response was the total number of beam crossings made in each 20 -min session.

\section{RESULTS}

An analysis of variance of the number of responses (beam crossings) made in the 20-min experimental period showed that the LSD-25 group responded significantly more than the saline control $(F=14.15$, df $=1 / 32, \mathrm{p}<.001)$. Neither the stimulus complexity difference nor the Drug by Stimulus Complexity interaction reached significance.

\section{DISCUSSION}

The experimental hypothesis was confirmed in that the LSD-25 groups inspected the stimulus card more (as measured in terms of beam crossings) than did the saline controls. The stimulus complexity variable was introduced on the assumption that the complex card, with its greater arousal potential, would elicit more responses. Thus, if the drug enhanced exploration, it should do so more in the "complex" than in the "simple" group. Although more responses were made to 


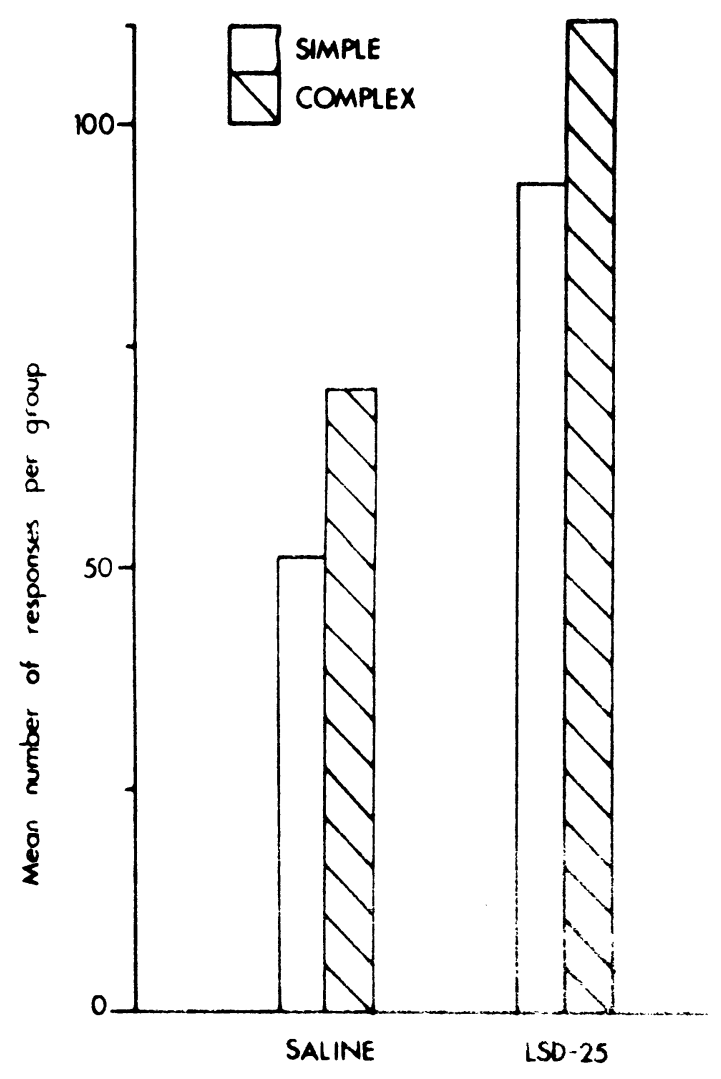

Fig. 1. Mean number of responses (beam crossings) per group $(\mathrm{N}=9)$ during the 20 -min session in the experimental box. the "complex" card, this difference failed to reach significance, as did the interaction of this dimension with the drug conditions. The result shows that drugs which apparently depress exploration when the response is for stimulation may have rather different effects when an animal is responding to stimulation.

Lowe and Williams (1972) showed that LSD-25 depressed responding for response-contingent light change at dose levels where there was no significant change in activity as measured in a no-change control condition. It could be, however, that these controls were not very sensitive and that the result was due, at least partly, to a general reduction in activity level. The present result renders this possibility unlikely, as here, at the same dose level of LSD-25, the drugged animals were significantly more active than the saline controls.

\section{REFERENCES}

Berlyne, D. E. The arousal and satiation of perceptual curiosity in the rat. Journal of Comparative \& Physiological Psychology, 1955, 48, 238-246.

Fowler, H. Curiosity and exploratory behavior. New York: Macmillan, 1965.

Lowe, G., \& Williams, D. I. The effects of hallucinogenic drugs on sensory reinforcement in the rat. Bulletin of the British Psychological Society, 1972, 25, 51A.

(Received for publication May 25, 1972; revision received September 12, 1972.) 